\title{
Development of advanced high porosity wicks for the high temperature heat pipes of concentrating solar power
}

\author{
Sergii Khairnasov ${ }^{1}$, Charles E. Andraka ${ }^{2}$, Volodymyr Baturkin ${ }^{1,3}$, Vladlen Zaripov ${ }^{1}$, \\ Oleksandr Nishchyk ${ }^{1}$ \\ ${ }^{1}$ Heat Pipes Laboratory of National Technical University of Ukraine “Kyiv Polytechnic Institute”, Peremogy Pr.37, Kyiv, 03056, \\ Kyiv,Ukraine, sergev.khairnasov@gmail.com,zaripoff@ukr.net, politex@voliacable.com, \\ ${ }^{2}$ Concentrating Solar Power Department 06123, Sandia National Laboratories, PO 5800 MS 1127, Albuquerque NM, \\ USA NM 87185, ceandra@ sandia.gov \\ ${ }^{3}$ Institute of Space Systems, Robert-Hooke-Straße 7, 28359 Bremen, Germany, volodymyr.baturkin@dlr.de
}

\begin{abstract}
Sandia National Laboratories and Heat Pipes Laboratory of National Technical University of Ukraine «KPI» developed several methods of improving robustness of the high-temperature heat pipe wick for their application to concentrating solar power (CSP) systems with stirling engine. In this case the wick structures must retain high heat pipe performance with robustness for long term operation. Recent modeling indicates that wicks based on various fiber combinations could provide the robustness combined with sufficient performance. Results of the development, characterization, modeling, and testing of an advanced felt metal wicks that addresses durability issues while maintaining sufficient performance are showed in the paper. The project resulted in an ongoing durability bench-scale heat pipe that simulates wick load conditions required for an $80 \mathrm{kWth}$ throughput solar receiver, including periodic nondestructive evaluation of the wick durability. Two mock-ups of high-temperature heat pipes were made for long life and performance tests: the first sample with wick based on $12 \mu \mathrm{m}$ felt; and second with hybrid wick based on $30 \mu \mathrm{m}$ felt and $6.5 \mu \mathrm{m}$ felt. Second heat pipe operation has continued unattended at $775^{\circ} \mathrm{C}$ vapor temperature for nearly 11,700 hours, with no observable loss of performance or change in startup characteristics.
\end{abstract}

Keywords: felt metal wick, high-temperature heat pipe, Stirling engine, concentrating solar power

\section{INTRODUCTION}

Sodium heat pipes have been identified as a potentially effective heat transport approach for CSP systems that require near-isothermal input to power cycles or storage, such as dish Stirling and highly recuperated reheat-cycle supercritical $\mathrm{CO}_{2}$ turbines [1]. Heat pipes offer high heat flux capabilities, leading to small receivers, as well as low exergetic losses through isothermal coupling with the engine. Sandia National Laboratories (SNL) developed a felt metal wick approach in the 1990's, and demonstrated very high performance [2]. However, multiple durability issues arose, primarily the structural collapse of the wick at temperature over short time periods and the wick separation from the substrate. SNL and Heat Pipes Laboratory of National technical university of Ukraine «KPI» (KPI) developed several methods of improving robustness of the wick, but the resulting wick had limited performance capabilities. For application to concentrating solar power (CSP) systems, the wick structures must retain high heat pipe performance with robustness for long term operation. So sintered felt wicks using a larger fiber with vapor vent features were developed, that addressed the key durability issues. However, performance was lost due to the larger fibers used. A sample tested at SNL indicated marginal performance, though it out-performed nickel powder wicks. Recent modeling indicates that wicks based on various fiber combinations could provide the robustness combined with sufficient performance.

By request of SNL, KPI in the context of previous researches [3] has analyzed wicks made of discrete metal fibers and intended for hightemperature heat pipes. This project provided for performance of a range of research activities aimed at creating of new advanced constructions of felt metal wicks with improved properties compared to previous ones. In particular, it was necessary to develop new constructions of the wicks, which will transmit much higher heat flow values. Such constructions must have good mechanical strength and mechanical contact with the substrate at high temperatures and, simultaneously, have high permeability at relatively low values of average and minimum pore sizes.

In this paper we report on the development, characterization and testing of an advanced felt metal wicks that addresses durability issues while 
maintaining sufficient performance. The project resulted in an ongoing durability bench-scale heat pipe that simulates wick load conditions required for an $80 \mathrm{kWth}$ throughput solar receiver, including periodic non-destructive evaluation of the wick durability.

\section{CREATION OF NEW ADVANCED WICKS CONSTRUCTIONS FOR THE HIGH-TEMPERATURE HEAT PIPE}

The maximal heat flux transmitted by a heat pipe (HP) $Q_{\max }$ during its work against gravity forces depends on: physical properties of a heat carrier (liquid), wick permeability $(L)$, area of its cross section, effective (average) sizes of pores, equivalent length of a heat carrier filtration path and ratio of hydrostatic pressure to the delivery capillary head.

Permeability of metal felt porous structures made of discrete fibers in direction along the plane of felting (along fibers) is in direct proportion to the effective (average) size of pores squared and inversely to the value $(1-\varepsilon)$, where $\varepsilon$ is a wick porosity, non-dimensional quantity. Effective (average) pore sizes of such wicks depend on the fiber diameter (to 0.7 power), fiber length (to 0.3 power) and the porosity $\varepsilon$.

To calculate the maximum heat flux $Q_{\max }$ transmitted by HP at its work against the forces of gravity, analytic dependencies NTUU KPI listed in the monograph [4] was used. These dependencies are intended for engineering calculations, and verified for the large number of experimental data. The maximum error of $95 \%$ of these data in comparison with the calculation of $Q_{\max }$ is less than $45 \%$.

The analysis of the obtained dependences has shown that the maximal heat flux $Q_{\max }$ increases at the rise of the wick porosity, decreasing of discrete fibers length and, especially, at reduction of their diameter.

Taking into account the designs of possible types of wicks, their merits and demerits, results of analytical research of different types of single-layer uniform wicks, the intention to increase the maximal heat flux $Q_{\max }$ (to $4 \mathrm{~kW}$ ), and also some results of experiments with fibers of different diameter and length, the following wick types of 5 $\mathrm{mm}$ thickness having optimal structural parameters, permeability and capillary head were offered with the next design parameters:

1. The type CS-22/3 made of $22-\mu \mathrm{m}$ discrete fibers $3 \mathrm{~mm}$ long: optimum porosity is 0.905 (within the range $0.87-0.91$ ), permeability - 510 $\mu \mathrm{m}^{2}$, diameters of pores: maximal $\left(D_{\max }\right)-255 \mu \mathrm{m}$, average $\left(D_{a v}\right)$ - $106 \mu \mathrm{m}$, minimum $\left(D_{\min }\right)-28 \mu \mathrm{m}$, delivery capillary head for sodium at $750{ }^{\circ} \mathrm{C}$ is $5000 \mathrm{~Pa}$.

2. The type CS-12/3 made of $12-\mu \mathrm{m}$ discrete fibers $3 \mathrm{~mm}$ long: optimum porosity is 0.955 (within the range 0.945-0.965), permeability $1160 \mu \mathrm{m}^{2}$, diameters of pores: maximal $-270 \mu \mathrm{m}$, average $-110 \mu \mathrm{m}$, minimum - $28.3 \mu \mathrm{m}$, delivery capillary head $-4820 \mathrm{~Pa}$.

3. The type CS-6.5/3 made of $6.5-\mu \mathrm{m}$ discrete fibers $3 \mathrm{~mm}$ long: optimum porosity is 0.98 (within the range from 0.97 - to maximum, 0.987), permeability $-2700 \mu \mathrm{m}^{2}$, diameters of pores: maximal - $278 \mu \mathrm{m}$, average - $112 \mu \mathrm{m}$, minimum $28.4 \mu \mathrm{m}$, delivery capillary head $-4740 \mathrm{~Pa}$.

4. The type CS-30/9 $+\mathbf{6 . 5 / 2}$ made of joint layout of $6.5-\mu \mathrm{m}$ fibers $2 \mathrm{~mm}$ long inside the structure made of the fibers with a diameter $\left(d_{f}\right)$ of $30 \mu \mathrm{m}$ and length $\left(l_{f}\right)$ of $9 \mathrm{~mm}$. The structural parameters of such wick, its permeability and capillary-transport properties and maximal heat flux $Q_{\max }$ are unknown for us and cannot be calculated at the moment.

Dependence of the estimated maximal possible maximal heat flux $Q_{\max }$ which can be transmitted by a heat pipe on the permeability $L$ of the first 3 wick types is shown in Fig. 1. At that the wick permeability is a function of wick porosity $\varepsilon$, diameter of the discrete fibers $d_{f}$ of the wick and their length $l_{f}$.

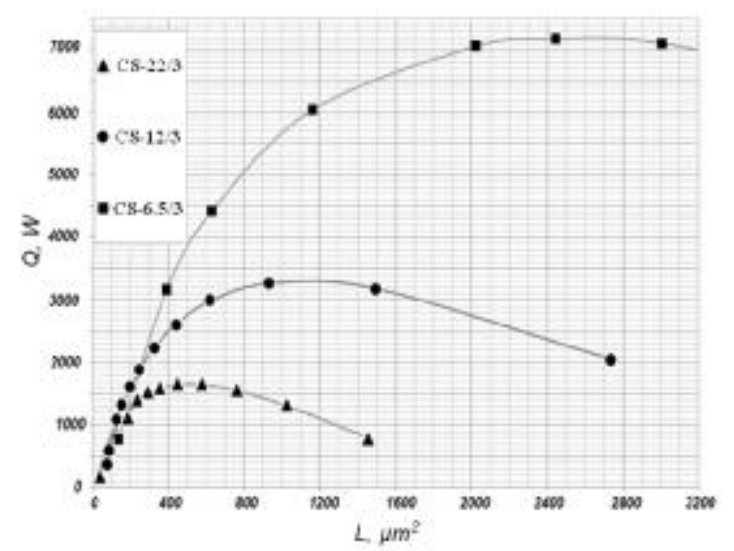

Fig. 1. Dependence of the estimated maximal heat flux transmitted by HP $Q_{\max }$ on the permeability of the wick with the thickness of $2.5 \mathrm{~mm}$.

Calculations are conducted without taking into account the influence of wick perforation and decrease of wick permeability along fibers because of pins inside the wick on $Q_{\max }$. The indicated factors will reduce the calculation values of $Q_{\max }$ approximately by $15-20 \%$. 


\section{EXPERIMENTAL RESEARCH OF PROPORTIONAL LIMIT AT ELONGATION OF THE WICKS MADE OF METAL DISCRETE FIBERS AT A TEMPERATURE OF $800^{\circ} \mathrm{C}$}

One of the main characteristics of capillary structures (CSs) used as the wicks for high temperature solar receiver is their mechanical durability at the working temperature. The experimental estimation of mechanical strength for CS samples of different designs has shown:

1. Mechanical strength of all the CS types, in particular, proportional limit (limit of elastic deformation at elongation), sharply decreases at the increasing of the temperature of CS exploitation and with the reduction of discrete fibers' diameter. The proportional limit goes down much less at the increase of CS porosity (against their maximum possible porosity).

2. Proportion limit of CS with porosity 0.92 made of fibers with a diameter of $30 \mu \mathrm{m}$ and $3 \mathrm{~mm}$ length decreases approximately by a factor of 10 at the increase of tests temperature from $20{ }^{\circ} \mathrm{C}$ to 750 ${ }^{\circ} \mathrm{C}$.

Seven long substrates $(140 \times 14 \times 1.5 \mathrm{~mm})$ of Haynes Alloy 230 with wick samples were made for mechanical tests. Four identical wicks were formed and sintered on each of 7 long substrates. The individual plates of stainless steel (for hanging of weights), with $20 \mathrm{~mm}$ length, $10 \mathrm{~mm}$ width, and thickness 0.2 and $0.8 \mathrm{~mm}$ were installed on other side of each identical wicks. Moreover the reinforced elements were set in the center of each identical wick on 3 of 7 long substrates. The reinforced elements were made by pins of stainless steel with a diameter of $0.5 \mathrm{~mm}$, and $4 \mathrm{~mm}$ high. Thus, after forming 3 long substrates included the reinforced elements of wicks and 4 long substrates didn't include them.

After sintering in a vacuum chamber at the temperature of $1200{ }^{\circ} \mathrm{C}$ during 2 hours the diameter of each cylindrical wick sample came to $10.0 \mathrm{~mm}$, height was from $3.5 \mathrm{~mm}$ to $5.3 \mathrm{~mm}$ with the given values of porosity.

One of the tested substrates with the CS samples was fastened to the framework, and then the weights having mass from $10 \mathrm{~g}$ to $200 \mathrm{~g}$ were hung under each sample of the given CS type. The weights masses were calculated so as to cover a range of loadings, both before and after the intended limit of proportionality occurrence.

Before setting into a furnace the thickness $\left(l_{l}\right)$ of each CS sample on the substrate was carefully measured by a micrometer, with precision of measurements not lower than $\pm 10 \mu \mathrm{m}$, and by an instrumental microscope, with precision of measurements not lower than $\pm 2 \mu \mathrm{m}$.

After obtaining of temperature of $800{ }^{\circ} \mathrm{C}$ inside the muffle, the experimental wick samples were kept at this temperature for 6 hours. After completion of tests and the muffle cooling-down to room temperature the framework was extracted from it, weights and the substrate with the samples were taken off.

The thickness $\left(l_{2}\right)$ of each sample was measured by the same instruments. The specific loadings, under which wick samples were at the temperature of $800{ }^{\circ} \mathrm{C}$, were calculated by the formula:

$$
\sigma=P / F,
$$

where $\sigma$ is the specific loading, $\mathrm{Pa}$; $\mathrm{P}$ is a weight of loads, $\mathrm{N}$; $\mathrm{F}$ is the area of wick contacting with plate, $\mathrm{m}^{2}$.

The relative increasing of sample thickness $\Delta l / l_{l}$ under influence of loading at high temperature was determined as a ratio of difference of thicknesses after tension of sample $l_{2}$ and before tests beginning $l_{1}$ to the thicknesses before tests beginning $l_{l}$. The experimental dependence of the applied specific loading $\sigma$ on the relative increasing of samples thickness $\Delta l / l_{1}$ is depicted in Fig. 2 for all the types of not reinforced wicks, and in Fig. 3 for reinforced wicks. The data are obtained for the samples of porous structures exposed to heating at the temperature of $800{ }^{\circ} \mathrm{C}$ during 6 hours.

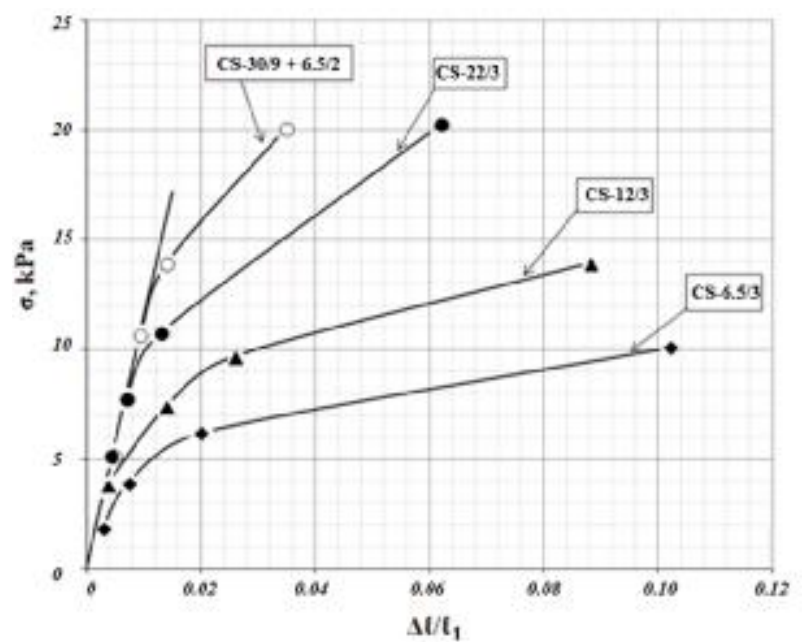

Fig. 2 Interdependence between applied specific loading and the relative increasing of the wick samples thickness $\Delta l / l_{l}$ (without reinforcement). 
On the tensile test diagrams presented in Figs. 2 and 3 one can mark out areas of proportionality of dependences $\Delta l / l_{1}=f(\sigma)$ and areas, where such proportionality is violated. These curvilinear areas (after a bend) are characterized by the fact that after unloading the wicks do not revert to the initial state. Therefore beginning of tension curve bend can be considered as the limit of elastic deformation, i.e. the proportional limit $\left(\sigma_{\text {lim }}\right)$ for the concrete wick design.

As follows from the Fig. 2, the wick samples CS-30/9 + 6.5/2 from mixture of 30- $\mu \mathrm{m}$ and 6.5$\mu \mathrm{m}$ fibers have the best curve of tension, and monodisperse homogeneous wicks from fine 6.5$\mu \mathrm{m}$ fibers possess the lowest mechanical strength.

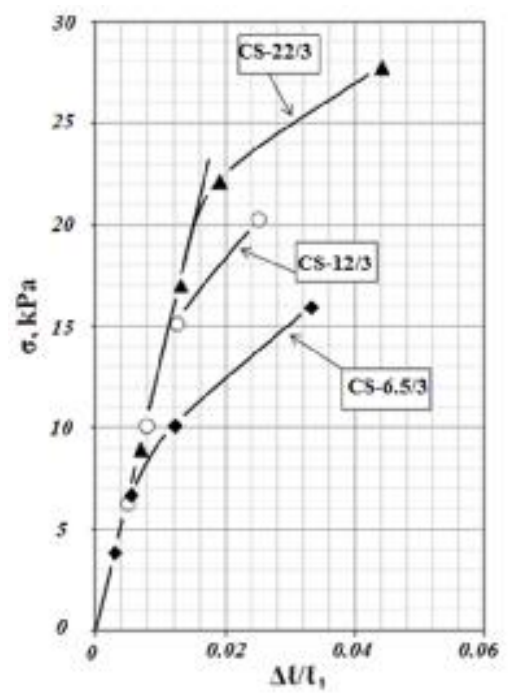

Fig. 3 Interdependence between applied specific loading and the relative increasing of the wick samples thickness $\Delta l / l_{l}$ (with reinforcement).

As well results (Fig.3) showed that the using within CS of reinforced elements as steel pins in the center of a sample considerably improves the high temperature tensile test diagrams, especially, in the case of fine $6.5-\mu \mathrm{m}$ and $12-\mu \mathrm{m}$ fibers. Thus as results:

1. Proportional limit of the offered advanced not reinforced designs of capillary structures exposed to heating at the temperature of $800{ }^{\circ} \mathrm{C}$ during 6 hours is within the range from $2 \mathrm{kPa}$ to $11.5 \mathrm{kPa}$. It considerably depends on the diameter of discrete fibers, sharply increasing with diameter enlarging.

2. Reinforcement of capillary structures by pins with a diameter of $0.5 \mathrm{~mm}$ increases their proportional limit considerably. For example, for CS made of fibers with a diameter of $6.5 \mu \mathrm{m}$ this value is 4 times greater, for $12 \mu \mathrm{m}$ fibers -3 times, and for $22 \mu \mathrm{m}$ fibers -2.6 times.

\section{EXPERIMENTAL RESEARCH OF HIGHLY POROUS WICKS' PERMEABILITY}

The permeability of porous materials is one of the most important capillary-transport characteristics, and it reflects the ability of a wick to pass working fluid. Fluid permeability coefficient describes the conductivity with respect to the fluid and is defined, basically, by structural characteristics of the porous material. In our case, they are: the wick's volume porosity, diameter and length of discrete metal fibers, and the direction of fluid filtration.

The main difficulty in conducting of experimental researches of metal-fibrous wicks' permeability is their extremely high porosity, which is close to the maximum achievable. Geometric dimensions of the tested samples were verified, and as a result deviations from the calculated values were found. At determining of the sample diameter given measurements took into account the wick's diameter instead of the disc diameter. The wick thickness was measured using a microscope and averaged over 4 circle points.

As a result of experiments and data processing values of the permeability coefficients were obtained for the wicks, as represented in the Table1.

Table 1 . The values of permeability and porosity for the wicks samples.

\begin{tabular}{|c|c|c|c|c|}
\hline $\begin{array}{c}\text { ㅅumber } \\
\text { of a } \\
\text { sample }\end{array}$ & $\begin{array}{c}\text { Fibers } \\
\text { diameter, } \\
\mu \mathrm{m}\end{array}$ & $\begin{array}{c}\text { Permeability } \\
\text { coefficients, } \\
\mu \mathrm{m}^{2}\end{array}$ & $\begin{array}{c}\text { Calcula- } \\
\text { ted } \\
\text { porosity }\end{array}$ & $\begin{array}{c}\text { Porosity } \\
\text { (by } \\
\text { satura- } \\
\text { tion) }\end{array}$ \\
\hline №1 & 22 & 215 & 0.91 & 0.932 \\
\hline №2 & 12 & 153 & 0.96 & 0.965 \\
\hline №3 & 6.5 & 488 & 0.95 & 0.979 \\
\hline №4 & $30+6.5$ & 193 & 0.96 & 0.956 \\
\hline №5 & 12 & 254 & 0.956 & 0.91 \\
\hline №6 & 6.5 & 302 & 0.983 & 0.952 \\
\hline
\end{tabular}

\section{EXPERIMENTAL RESULTS OF PORE SIZE DISTRIBUTION IN HIGHLY POROUS METAL-FIBROUS WICKS}

An advantage of porous materials produced from fibers, wire or mesh is practical absence of closed and blind pores at a porosity $\varepsilon>0.1$ [5]. When the porous body is considered only as permeable to gases and liquids medium the model used represents the real permeable medium as a system of cylindrical capillaries of constant cross- 
section that are parallel to each other and to passing through it flow [6]. Pore size distribution gives the most complete picture of the structure and uniformity (proximity of pore sizes values from maximum to minimum) of a porous material. The most common way to determine the pore size distribution, or rather the volume occupied by pores of a certain size, is the method of mercury porosimetry, based on the property of many solids non-wetting by mercury.

To determine the pore size distribution or pore volume of each size in the range of the pore sizes within the porous material of a given porosity two sample types were made: the first type had a shape of a cylinder with a diameter of $10 \mathrm{~mm}$ and of 20 mm height (Fig. 4, a), and the second type had a shape of a parallelepiped with a base of $10 \times 6 \mathrm{~mm}$ and $20 \mathrm{~mm}$ height (Fig. 4, b). The samples were manufactured by air felting using molds. Diffusion welding was carried out in a vacuum furnace at a temperature of $1200{ }^{\circ} \mathrm{C}$ for 2 hours at a vacuum level of $10^{-4} \mathrm{mmHg}\left(1.33 \cdot 10^{-4} \mathrm{~Pa}\right)$. Total amount of the sample groups selected for the test was 4 .

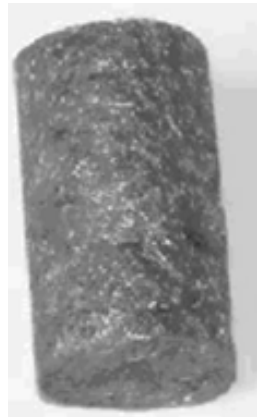

(a)

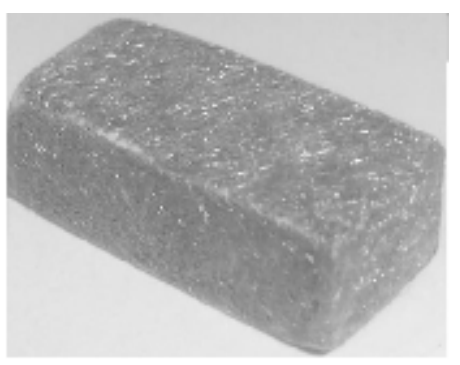

(b)
Fig. 4 The samples for mercury porosimetry: a) made as cylinders, b) made as parallelepipeds.

Table 2 summarizes the data on the calculated and experimental values of average $D_{a v}$, maximum $D_{\max }$ and minimum $D_{\min }$ pore sizes.

Table 2. The data on the calculated and experimental values of average, maximum and minimum pore sizes.

\begin{tabular}{|c|c|c|c|c|c|c|}
\hline $\mathrm{N}$ & $d_{f}(\mu \mathrm{m}) /$ & $\varepsilon_{\text {calc }}$ & $\varepsilon_{\text {exp }}$ & $\begin{array}{c}D_{\text {av, calc }} \\
D_{\text {av, exp, }}, \\
\mu \mathrm{mm})\end{array}$ & $\begin{array}{c}D_{\text {max, cald }} \\
D_{\text {max, exp }}, \\
\mu \mathrm{m}\end{array}$ & $\begin{array}{c}D_{\text {min, cald }} \\
D_{\text {min.exp }}, \\
\mu \mathrm{m}\end{array}$ \\
\hline 1 & $22 / 3$ & 0.903 & 0.903 & $104.8 / 117$ & $251.5 / 277$ & $27.9 / 22$ \\
\hline 2 & $12 / 3$ & 0.922 & 0.906 & $70.3 / 71.1$ & $168.9 / 166.5$ & $18.6 / 15.5$ \\
\hline 3 & $12 / 3$ & 0.956 & 0.946 & $98.9 / 111.9$ & $241.4 / 333$ & $25.6 / 26.5$ \\
\hline 4 & $6.5 / 3$ & 0.957 & 0.951 & $68.0 / 79.1$ & $166.7 / 166.5$ & $17.5 / 16.5$ \\
\hline 5 & $6.5 / 3$ & 0.959 & 0.943 & $62.4 / 72.5$ & $152.3 / 166.5$ & $16.2 / 14.7$ \\
\hline 6 & $\begin{array}{c}6.5 / 2+ \\
30 / 9\end{array}$ & 0.963 & 0.959 & $-/ 100.3$ & $-/ 166.5$ & $-/ 16.5$ \\
\hline
\end{tabular}

Experimental values of pore size are obtained using mercury porosimetry method. As a result of mercury porosimetry, experimental integral and differential distribution of the pore's size of the relative volume were obtained for studied samples, for example see Fig. 5 (samples N 2 and N 6). Table 2 represents experimental average pore sizes $\left(D_{a v}, \quad\right.$ exp $)$. Experimental maximum pore sizes $\left(D_{\max }\right.$, exp $)$ and experimental minimum pore sizes $\left(D_{\text {min. exp }}\right)$ are obtained by processing data taking into account their calculated values obtained by dependencies (3) and (4) respectively.

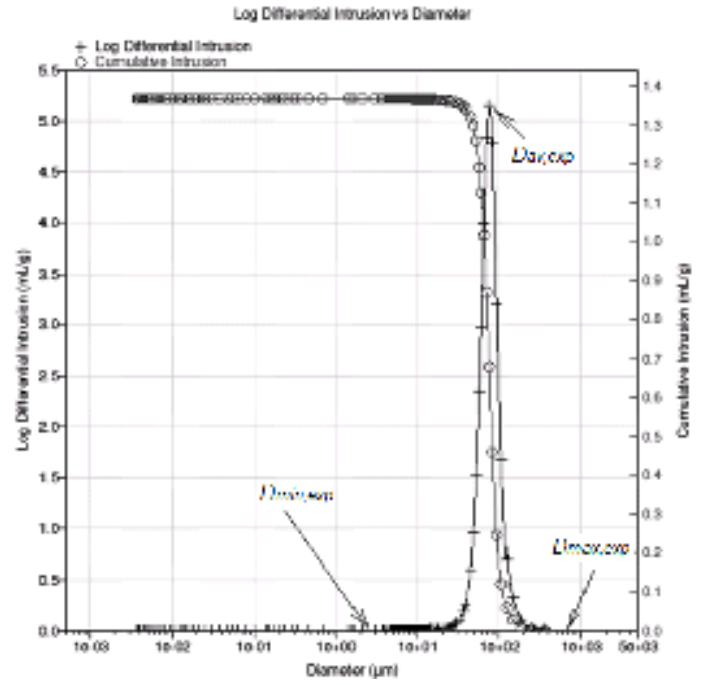

(a)

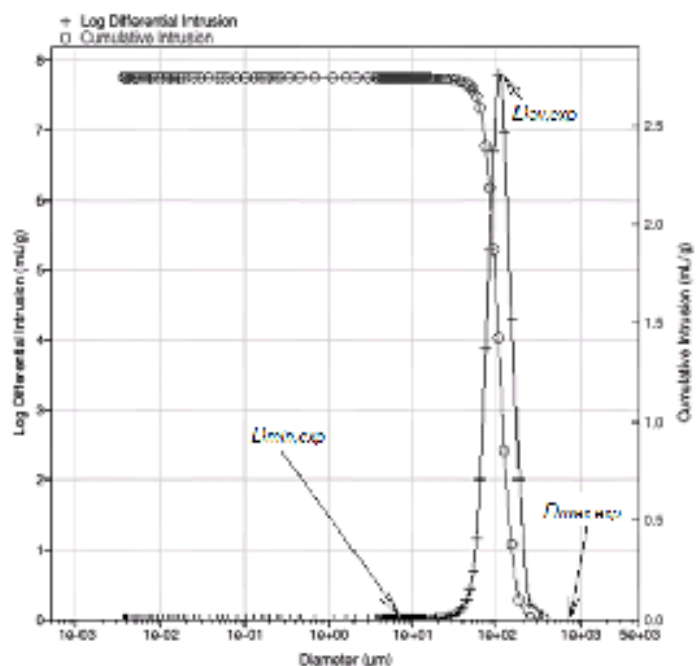

(b)

Fig. 5. Experimental integral and differential distribution of the pore size relative volume $(\mathrm{mL} / \mathrm{g})$ for the sample: $\mathrm{N} 2$ and $\mathrm{N} 6$ (Table 2).

Calculation dependences NTUU KPI for determining of the average, maximum and minimum pore sizes, depending on the dimensions of the metal-fibrous porous material structural 
components $\left(d_{f}\right.$ and $\left.l_{f}\right)$, and the porosity of the material $\varepsilon$ are represented below:

$$
\begin{aligned}
D_{a v} & =0.4 d_{f}^{0.7} l_{f}^{0.3} \frac{\varepsilon^{1.6}}{\sqrt{(1-\varepsilon)}}, \\
D_{\max } & =d_{f}^{0.7} l_{f}^{0.3} \frac{\varepsilon^{2}}{\sqrt{(1-\varepsilon)}}, \\
D_{\min } & =0.1 d_{f}^{0.7} l_{f}^{0.3} \frac{\varepsilon}{\sqrt{(1-\varepsilon)}} .
\end{aligned}
$$

Average calculated pore sizes $\left(D_{a v}\right.$, calc $)$ are obtained using formula (2), the maximum calculated pore sizes $\left(D_{\max , \text { calc }}\right)$ are obtained using formula (3), and the minimum calculated pore sizes $\left(D_{\text {min, calc }}\right)$ are obtained using formula (4). At computation of the average calculated pore sizes $D_{a v}$, calc, maximum calculated pore sizes $D_{\max }$, calc and minimum calculated pore sizes $D_{\min }$, calc experimental values of porosity obtained by mercury porosimetry were used.

Calculated porosity $\left(\varepsilon_{\text {calc }}\right)$ was computed using mass $\mathrm{m}$ and volume $\mathrm{V}$ of the sample taking into account the density $\rho$ of fiber material

$$
\varepsilon_{\text {calc }}=1-\frac{m}{V \cdot \rho} .
$$

Experimental porosity is determined by the mercury porosimetry method and by liquid saturation.

It is not possible to calculate the pore size of the porous material made of the mixture of fibers: 1) with a diameter of $30 \mu \mathrm{m}$ and $9 \mathrm{~mm}$ length; 2) with a diameter of $6.5 \mu \mathrm{m}$ and $2 \mathrm{~mm}$ length $(6.5 / 2+30 / 9$ in the Table. 2) since method of the pore size computation hasn't been developed for the porous materials composed of fibers of different diameters and lengths.

The resulting experimental determination of pore size distribution in the metal-fibrous wick obtained by mercury porosimetry correspond fairly closely with the calculated values obtained by computation of formulae, developed in the laboratory of heat pipes on basis of NTUU "KPI". In particular this applies to the average pore sizes. Determination of maximum and minimum pore sizes using experimental distributions is complicated because it is difficult to determine precisely the points on the distribution curve (especially for the minimum pore size), which can be considered appropriate to minimum and maximum pore sizes (see Fig. 5, a, b). In this case calculation of the corresponding values of pore sizes by formulae developed in the NTUU "KPI" is a considerable help, which avoids big mistakes. As it turned out when comparing the experimental and calculated data (see Table. 2), formulae previously obtained in the NTUU "KPI" can be applied for calculation of the average, minimum and maximum pore sizes for a porous material made of fibers with a size that differs from that ones studied before. These formulas can be recommended for use in the calculations of the structural parameters for porous materials made of fibers with a diameter of $22 \mu \mathrm{m}$ as well as a diameter of $12 \mu \mathrm{m}$ and a diameter of $6.5 \mu \mathrm{m}$. The pore sizes of the porous material made of a mixture of fibers with different diameters and lengths can only be determined experimentally.

\section{TESTING OF HIGHLY POROUS METAL-FIBROUS DETACHMENT FROM METAL SUBSTRATES}

To assess the mechanical properties of porous materials the following common characteristics are used: tensile strength (limit of proportionality at elongation), compressive and shear strength, elongation, impact strength [5].

Porous samples manufactured on the substrates made of Haynees Alloy 230 50x50 mm, were subject to the experiments determining detachment of the porous material of $5 \mathrm{~mm}$ height (Fig. 6). This material was sintered to the substrates in a vacuum oven at a temperature of $1200{ }^{\circ} \mathrm{C}$ for 2 hours at a vacuum level of $10^{-4} \mathrm{mmHg}\left(1.33 \cdot 10^{-4} \mathrm{~Pa}\right)$. Amount of fibers remaining on the substrate after separation of the porous material main body, and the uniformity of the fibers remaining on the detachment surface were assessed on $5 \times 5 \mathrm{~mm}$ area of the substrate.

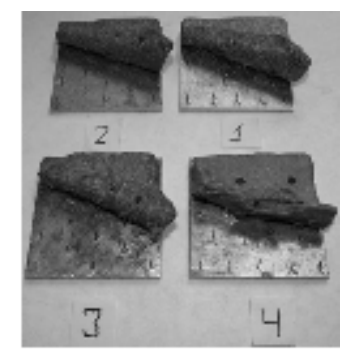

Fig. 6 Porous samples on the substrates made of Haynes Alloy 230 of 50x50 mm size after detachment test.

Mechanical properties $\left(\sigma_{\text {temp }}\right)$ on the boundary compact material - porous material were determined by the value $\sigma_{\text {temp }}$ of the porous material. The value $\sigma_{\text {temp }}$ for the steel $316 \mathrm{~L}$ is: 
1. In accordance with EN 10088-2, $\sigma_{\text {temp }} \geq 520$, $\mathrm{N} / \mathrm{mm}^{2}$;

2. In accordance with ASTM A $240, \sigma_{\text {temp }} \geq 515$, $\mathrm{N} / \mathrm{mm}^{2}$.

3. The typical value of temporary resistance for the fibers' material (steel $316 \mathrm{~L}$ ) is $\sigma_{\text {temp }}=570$ $\mathrm{N} / \mathrm{mm}^{2}$, minimal value of temporary resistance for the fibers' material is $\sigma_{\text {temp }}=485 \mathrm{~N} / \mathrm{mm}^{2}$.

According to the results of detachment test for the porous samples made of fibers (fiber material is steel 316L) and sintered to the substrates (substrate material is HAYNES ALLOY 230) of $50 \times 50 \mathrm{~mm}$ size:

a) for all the samples the good quality of porous material sintering to the substrates was provided;

b) decreasing of fiber diameter improves sintering quality (more fibers remaining on the substrates).

Reinforcement of the porous material by pins increases detachment force in the plane perpendicular to the orientation of the pins. Separation of the porous material was carried out from pin to pin by snaps at about equal force applied during this operation. Reinforcing of the porous material by pins improves adhesion of the porous material to the substrate.

Additional mechanical tests with fibers made of 316L steel with the following dimensions: $12 \mu \mathrm{m}$ diameter, $3 \mathrm{~mm}$ length (total dimensions of flat bar \#1 is $561,5 \times 57 \mathrm{~mm}$ ), and a mixture of fibers with the following dimensions: 1) $30 \mu \mathrm{m}$ diameter, 9 mm length; 2) $6.5 \mu \mathrm{m}$ diameter, $2 \mathrm{~mm}$ length (total dimensions of flat bar \#2 561,5 x $57 \mathrm{~mm}$ ) were carried out.

The entire surface of the flat bar \#1 is uniformly dotted by fibers that remained after the separation of the porous material, there is no areas without fibers. A number of remaining fibers on the detailed $5 \times 5 \mathrm{~mm}$ platforms was $20-45$ pieces.

The entire surface of the flat bar \#2 is uniformly dotted by fibers of the larger $(30 \mu \mathrm{m}$ diameter, 9 $\mathrm{mm}$ length) and the smaller (6.5 $\mu \mathrm{m}$ diameter, 2 $\mathrm{mm}$ length) sizes that remained after the separation of the porous material, there is no areas without fibers, and there are some areas with more thick fiber layers remained on the substrate. A number of remaining fibers on the detailed $5 \times 5 \mathrm{~mm}$ platforms was 20-110 pieces.

According to the results of the test of the porous samples (made of steel 316L fibers) detachment from the substrates in the form of the flat bars (made of HAYNES ALLOY 230) with 561,5 x57 $\mathrm{mm}$ size, all samples have good quality of the porous material sintering to the substrate.
Decreasing of the fiber diameter improves sintering quality, this means that more fibers remain on the substrates. Reinforcement of the porous material by pins increases detachment force in the plane perpendicular to the orientation of the pins. Separation of the porous material was carried out from pin to pin by snaps at about equal force applied during this operation. Arrangement of the steam-out channels has no significant effect on the porous material detachment force. Reinforcing of the porous material by pins improves adhesion of the porous material to the substrate.

\section{MANUFACTURING OF FULL-SCALE SAMPLES OF ADVANCED WICKS FOR HIGH-TEMPERATURE HOURGLASS HEAT PIPES AND THEIR TEST}

3 full-scale samples on substrates 57-by-560 $\mathrm{mm}$ for tests in heat pipes of SNL were produced: two samples based on the material made of felt with diameters $12 \mu \mathrm{m}$ and $3 \mu \mathrm{mm}$ length; one sample based on the hybrid porous material made of a mixture of felts with diameters of $30 \mu \mathrm{m}(9$ mm length) and with a diameter of $6.5 \mu \mathrm{m}(2 \mathrm{~mm}$ length) (fig. 7).

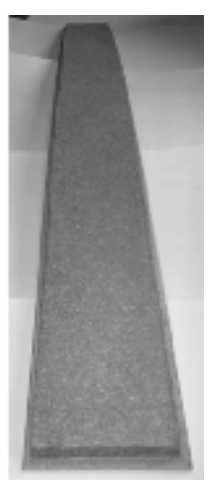

(a)

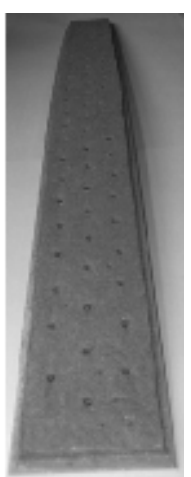

(b)
Fig. 7 The flat bar (full-scale samples): a - with diameters $12 \mu \mathrm{m}$ and $3 \mathrm{~mm}$ length; $b$ - with diameters of $30 \mu \mathrm{m}(9 \mathrm{~mm}$ length) and with a diameter of $6.5 \mu \mathrm{m}(2$ $\mathrm{mm}$ length).

Tests results showed that the materials made of felt with a diameter of $12 \mu \mathrm{m}$ had stable characteristics: dimensions of full-scale samples, the uniformity of the structure and the absence of wick delamination from the substrate. The hybrid porous material made of a mixture of felts with diameters of $30 \mu \mathrm{m}$ and $6.5 \mu \mathrm{m}$ is also promising for the HPs. However, the manufacturing technology for the porous hybrid material made of a mixture of felts cannot be finally provided: repeatability of the structural and capillary 
transport properties of the HP and receiving of preset wicks parameters. So they need a subsequent additional research and technological works.

Two mock-ups of high-temperature heat pipes were made in SNL for long life and performance tests: the first sample with wick based on $12 \mu \mathrm{m}$ felt (length of $3 \mathrm{~mm}$ ); and second with hybrid wick based on $30 \mu \mathrm{m}$ felt (9 mm length) and $6.5 \mu \mathrm{m}$ felt (2 mm length). Second heat pipe operation has continued unattended at $775^{\circ} \mathrm{C}$ vapor temperature for nearly 11,700 hours, with no observable loss of performance or change in startup characteristics. Prior felt wick heat pipes would lose most of the wick thickness through compression in the heated zone in the first 500 hours, compressing to under $1 \mathrm{~mm}$ thickness and failing to sustain operation without thermal crisis. The wick thickness at 1000, 2500, and 5000 hours was inspected using x-ray computed tomography, and $3 \%$ reduction in wick thickness was observed. As well a slightly concave surface of the wick between support pins was discovered, confirming that the pins are providing suitable support of the wick structure. The test is planned to continue to 20,000 hours, followed by destructive evaluation of the wick to verify the structural and chemical durability of the selected wick structure.

\section{CONCLUSIONS}

The research works were focused on creation and investigation of felt metal wicks based on: the fiber diameter of $22 \mu \mathrm{m}$ and discrete fiber length of $3 \mathrm{~mm}(22 \mu \mathrm{m} / 3 \mathrm{~mm})$; on fiberes $12 \mu \mathrm{m} / 3 \mu \mathrm{mm}$; on fibers $6.5 \mu \mathrm{m} / 3 \mathrm{~mm}$. As well hybrid porous material based on mixture of fibers with diameter of $30 \mu \mathrm{m}$ (fiber length $9 \mathrm{~mm}$ ) and diameter of 6.5 $\mu \mathrm{m}$ ( $2 \mathrm{~mm}$ length) was investigated. All wicks had maximal possible porosity, laying in range 0.910.95 .

Pore size distribution for advanced wicks were investigated by mercury porosimetry. The resulting experimental pore size distribution in the felt metal wick obtained by mercury porosimetry correspond fairly closely with the calculated values obtained by computation of formulas, developed in NTUU KPI. The formulas can be recommended for use in the calculations of the structural parameters for porous materials made of felt with a diameter of 22 $\mu \mathrm{m}$ as well as a diameter of $12 \mu \mathrm{m}$ and a diameter of $6.5 \mu \mathrm{m}$. The pore sizes of the porous material made of a mixture of felts with different diameters and lengths can only be determined experimentally.
The mechanical testing of highly porous felt metal wicks' detachment from metal substrates were performed. The mechanical properties of porous permeable materials depend on the mechanical properties of the felts material, felts fiber diameters, material porosity, number and size of contact between the particles after sintering. The dimensional stability of system "wick-substrate" were ensured by the staggered mounting of the pins made of stainless steel $0.5 \mathrm{~mm}$ in diameter and with a height of $4 \mathrm{~mm}$, penetrating the porous material.

Two mock-ups of high-temperature heat pipes were made in SNL for long life and performance tests. Heat pipe operation has continued unattended at $775^{\circ} \mathrm{C}$ vapor temperature for nearly 11,700 hours, with no observable loss of performance or change in startup characteristics. The test is planned to continue to 20,000 hours, followed by destructive evaluation of the wick to verify the structural and chemical durability of the selected wick structure.

\section{ACKNOWLEDGEMENT}

Sandia National Laboratories a multi-program laboratory managed and operated by Sandia Corporation, a wholly owned subsidiary of Lockheed martin Corporation, for the U.S. Department of Energy's national Nuclear Security Administration under contract DE-AC0494AL85000. We acknowledge the funding support of the DOE SunSHOT program for this project, a part of the Dish Stirling High Performance Thermal Storage project. In addition authors express their gratitude to Scientific and Technological Center of Ukraine for support of the Project \# 577.

\section{REFERENCES}

[1] C. E. Andraka, D. R. Adkins, T. A. Moss, H. M. Cole and N. H. Andreas, in ASME SED Conference (ASME, Maui, HI, 1995).

[2] C. E. Andraka, K. S. Rawlinson, T. A. Moss, D. R. Adkins, J. B. Moreno, D. R. Gallup, P. G. Cordeiro and S. Johansson, Proc Iecec, 1295-1300 (1996)

[3] V. Baturkin, V. Zaripov, C. E. Andraka and T. A. Moss, Solar Engineering 2005, 679-685 (2006).

[4] Semena M.G., Gershuni A.N., Zaripov V.K. "Heat pipes with metal felt capillary structures". - Kiev: Vyshcha shcola, 1984. - 215 p.

[5] Porous permeable materials: Ref. ed. / Ed. Belov S.V. - M.: Metallurgy, 1987. - 335 p.

[6] A.G. Kostornov. Permeable metal fiber materials. Kiev: Technology, 1983. - 128 p. 